\title{
Bridging the gap in rheumatology
}

\author{
Janet E McDonagh, Taunton R Southwood, Clive A J Ryder
}

\begin{abstract}
Case history
PRESENTATION AND MANAGEMENT

Louise is now 18 years old. She is white and developed erosive, polyarticular psoriatic arthritis with significant skin involvement when she was 10 years old. She was referred to the paediatric rheumatology team at the age of 13 having previously been treated with nonsteroidal anti-inflammatory drugs, sulfasalazine and intra-articular corticosteroids. She was subsequently treated with further multiple intra-articular corticosteroid injections under general anaesthetic, oral methotrexate (maximum $20 \mathrm{mg} /$ week) and naproxen $(20 \mathrm{mg} / \mathrm{kg} /$ day).
\end{abstract}

Her disease failed to remit and oral methotrexate was replaced with weekly subcutaneous methotrexate (maximum $25 \mathrm{mg} /$ week, given by Louise's mother) and continuous oral daily prednisolone $(0.5 \mathrm{mg} / \mathrm{kg} /$ day $)$. After three months of subcutaneous methotrexate treatment, Louise developed persistently abnormal liver function tests (maximum alanine transaminase $(\mathrm{ALT})=286 \mathrm{IU} / \mathrm{l}$, alkaline phosphatase $($ ALP $)=718 \mathrm{IU} / \mathrm{l})$. Methotrexate was subsequently omitted and re-introduced at a lower dose but to the detriment of the arthritis, which flared requiring increased prednisolone treatment. In view of the desire to continue methotrexate, a liver biopsy was performed that showed only sinusoidal dilatation with no chronic damage evident. The methotrexate was continued and a repeat liver biopsy a year later remained unchanged. The liver function tests gradually resolved with control of the disease and are currently as follows: ALT $=17 \mathrm{IU} / 1$, $\mathrm{ALP}=339 \mathrm{IU} / 1$.

When Louise was 15 years old, in view of the difficulty controlling her disease without concomitant oral corticosteroids, potential addition of cyclosporin was discussed. She adamantly refused this medication in view of the potential side effects, particularly the hirsuitism and gum hyperplasia. As a compromise, she agreed to take sulfsalazine but tolerated only the addition of $500 \mathrm{mg}$ daily. However, her arthritis and acute phase response steadily improved after its introduction (after four months, erythrocyte sedimentation rate (ESR) $=25 \mathrm{~mm} 1 \mathrm{st} \mathrm{h}, \mathrm{C}$ reactive protein $(\mathrm{CRP})=$ $13 \mathrm{mg} / \mathrm{l})$. She is currently prescribed weekly 35 mg subcutaneous methotrexate administered by her mother, $1 \mathrm{mg}$ prednisolone daily, 500 $\mathrm{mg}$ sulfasalazine, naproxen $20 \mathrm{mg} / \mathrm{kg} /$ day and Microgynon. Her psoriasis is currently control- led with topical corticosteroids and intermittent ultraviolet B light treatment. During the course of her illness, she was admitted as a day case for multiple intra-articular corticosteroid injections under either general anaesthetic or sedation. Within the past year she has also had a knee injected without sedation. Clinically her disease is in remission although unfortunately her ESR has recently begun to increase again $(\mathrm{ESR}=95 \mathrm{~mm} \mathrm{~mm} \mathrm{1st} \mathrm{h).} \mathrm{Erosive} \mathrm{disease} \mathrm{is}$ evident radiologically. She currently reports a Childhood Health Assessment Questionnaire score of 1.62 (a functional assessment tool validated for use in children with juvenile arthritis aged $1-19$ years; range 0 (no difficulty) to 3 (severe functional limitation). ${ }^{1}$ She uses a wheelchair occasionally for long distances.

\section{COMPLIANCE}

There is concern regarding compliance with her oral medication that her mother continues to supervise. Louise refuses to self administer her subcutaneous methotrexate despite various attempts by the rheumatology specialist nurse, including meeting other young people with juvenile idiopathic arthritis (JIA) who successfully self inject. In addition, she admits to noncompliance with her daily home exercises, does no regular exercise and refuses to wear any wrist splints, resting or working.

\section{BODY IMAGE}

Louise has now been taking prednisolone for four years and has been significantly cushingoid for prolonged periods during the course of her arthritis with significant striae. Her weight peaked at the 90th centile and currently lies between the 75th and 90th centile. Her height has remained on the 50th centile. The corticosteroid induced weight gain has been compounded by her "comfort eating" and erratic eating behaviour, for example, excessive in between meal snacking. Her mother recalls finding Louise in the kitchen late at night emptying the fridge of its edible contents! Louise has insight into her eating behaviour and has admitted to both her distress regarding her weight gain yet helplessness to change it significantly.

Menstruation eventually started when Louise was 16 but her periods became heavy and irregular lasting seven days in a two week cycle. At times the menorrhagia prevented her from participating in her regular hydrotherapy sessions. She was subsequently referred to an 
Table 1 Issues at transfer from paediatric to adult rheumatology care

- Severe erosive polyarthritis, recently controlled

- Abnormal liver function tests on methotrexate - ? advice regarding future alcohol intake

- Long term prednisolone treatment - ? bone mass

- Contraceptive advice if discontinues microgynon and becomes sexually active

- Poor compliance with drugs, splints and physiotherapy

- Further intra-articular injections without sedation

- Independence in health care, for example, seeing health professionals independently, self medication

- Level of parental concern

- Limited psychosocial support beyond family

- Career choices

- Smoking

- Unsatisfactory transfer to adult services

adult gynaecologist who prescribed Microgynon. This has improved the dysmenorrhoea but Louise feels merely compounds her weight gain and wishes to stop the treatment.

SOCIAL HISTORY

Louise lives at home with her parents and younger brother. At the age of 13, she was experiencing bullying at school and subsequently became increasingly moody at home. The latter was observed at clinic visits when Louise would sit with head down, avoiding eye contact and was very uncommunicative, her mother answering most of the questions. Her social life was limited and she had few close friends. On reporting these issues in addition to her low mood, the school and community paediatrician supported a referral to a clinical psychologist when Louise was 15 years old.

EDUCATION

Louise received a statement of special educational needs within one year of disease onset but unfortunately still lost a major amount of schooling. Within the first year of care at the paediatric rheumatology centre, in addition to frequent outpatient clinic visits to a variety of professionals, she was an inpatient on nine occasions, one admission lasting three weeks. When asked why she felt unable to attend school she replied it was "due to tiredness, poor concentration and pain". Bullying was later identified as a further contributing factor to school absence. For over two years, she only attended for afternoons and otherwise had home tuition. Despite this, Louise obtained seven GCSE and is now studying for three A levels. She does not know what she wants to do when she leaves school and has not participated in any work experience to date.

\section{HEALTH CARE}

Louise was initially seen in the general paediatric rheumatology clinic and transferred to the adolescent clinic when she was 15 years old. One or both parents still attend clinic appointments with her but she has been seen independently from her parents during her visits since she was 16 years old. This change coincided with a positive change in her demeanour in clinic and her announcement that she wished to start driving lessons. Unfortunately her enthusiasm was not shared with her mother who expressed concern regarding Louise's potential ability to drive safely. She however successfully passed her driving test and manages to drive a standard car. Once the independent visits became established, Louise confided that she was smoking five cigarettes a day though denied any alcohol intake. It also transpired that she has a boyfriend who her parents do not approve of, but she denied sexual activity.

TRANSFER TO ADULT HEALTH CARE

As she approached her 18th birthday, after discussion with Louise and her parents, it was decided to transfer her to the care of a local adult rheumatologist, distant from her paediatric care centre. Although the latter was willing to take over care, an appointment was not received until 10 months later. She attended the adult rheumatology clinic with her parents and was seen, with them in attendance, by the senior house officer (non-career training grade). Concern regarding the transfer arrangements was expressed by both Louise and her parents at the subsequent overlap visit with the paediatric rheumatologist and they remain under dual follow up at the time of writing. Table 1 summarises the current issues at time of transfer to adult rheumatology care.

\section{Discussion}

The needs of adolescents with arthritis were recently highlighted by the Arthritis Research Campaign in the Education Week (January 1999). A recent audit of services for these young people by the British Paediatric Rheumatology Group identified a need for service development in this area with only $18 \%$ of paediatric rheumatology services reporting a dedicated adolescent clinic (McDonagh JE, unpublished data). This deficiency is not isolated to rheumatology. A recent survey of all the health authorities in the UK reported only $9.8 \%$ of health authorities having adolescent specifications. ${ }^{2}$ This case history attempts to illustrate the integrated and developmentally appropriate care such young people need at this important time of their lives.

IS JIA A DISEASE ONLY OF CHILDHOOD OR DOES IT PERSIST INTO ADULTHOOD?

Louise is entering adulthood with significant disease activity requiring medication, in addition to having significant damage attributable to previous disease activity. Juvenile idiopathic arthritides encompass seven disease subsets of which psoriatic arthritis is one. ${ }^{3}$ One in three patients with JIA will have active disease in adulthood $^{45}$ and up to $60 \%$ will experience limitation in activities in daily living because of their arthritis. ${ }^{67}$ Complications of ongoing or previous treatment may also become increasingly apparent in adulthood, for example, corticosteroid induced osteoporosis, need for joint replacement surgery, amyloidosis. Children and adolescents with arthritis have reduced bone mineral density compared with healthy counterparts. ${ }^{8}$ Any relative impairment in bone formation will have an accentuated effect during the adolescent years when bone acquisition would normally be at its maximum. In view of her severe active disease and long term corticosteroid use, Louise is at risk of osteoporosis and this will need to be monitored. 
HOW CAN HEALTH PROFESSIONALS BEST DEAL WITH POOR COMPLIANCE IN ADOLESCENTS WITH JIA?

It is important to consider the issues underlying the young person's reluctance to adhere to treatment regimens. When Louise's poor compliance with drugs was discussed with her, one of her main concerns was the confusion arising from the differences between generic and proprietary names of drugs. She worried that she was receiving the wrong drugs if the names differed from previous prescriptions and refused to take them. Furthermore, the impact of having the liver biopsy was significant in psychological terms as it highlighted the potential risks of drug treatment. Her anxiety is reflected in her reluctance to self administer her methotrexate. It is important that poor compliance is not seen as a negative, destructive behaviour but rather the issues underlying the poor compliance are tackled. It may be the young person's only channel to express their evolving wish for independence. To this end, encouraging self medication by the patient and gradual relinquishment of the role of supervisor by the parent are important areas of transitional care for health professionals to consider.

Wrist and finger splints are very visible markers of the difference between Louise and her peers and the reasons behind noncompliance with splints are not difficult to appreciate. Occasionally, with the expertise of an occupational therapist, such splints can be transformed into fashion accessories.

Compliance in adolescent health care must be kept in context and not over emphasised especially as it is estimated that $25-95 \%$ of adult outpatients do not take their medications as prescribed. ${ }^{9}$

WHY IS BODY IMAGE SUCH AN IMPORTANT CONSIDERATION IN THE MANAGEMENT OF ADOLESCENTS WITH JIA?

Body image is closely related to emotional well being in adolescence ${ }^{10}$ and may have reciprocal influences on the management of a young person with JIA. Adolescent physical development and hence body image can be affected both by the disease, for example, joint deformity, growth retardation, pubertal delay, skin involvement, for example, psoriasis, in addition to adverse effects of treatment, for example, corticosteroid induced weight gain. Pubertal delay, even in healthy adolescents, may cause considerable psychological distress. ${ }^{11}$ Louise had several body image issues during the course of her arthritis. When Louise's periods began, they caused further distress with dysfunctional bleeding, often seen with chronic inflammatory diseases ${ }^{12}$ and which interfered with her hydrotherapy. She was non-compliant with splints because of their appearance especially when viewed by her peers. She was very self conscious about her weight, which was compounded by her corticosteroid treatment and eating habits and in her opinion, Microgynon. Fortunately the psoriasis has remained well controlled to date.
IN WHAT OTHER ASPECTS WAS LOUISE'S ADOLESCENT DEVELOPMENT AFFECTED BY HER ARTHRITIS?

Louise's significant school absence in addition to her depression, fatigue and pain potentially could affect her cognitive development. Lovell et al report an average school absence rate for children with arthritis of 12 days per school year compared with a national average of five days per year. ${ }^{13}$ Maximising school attendance is vital during adolescence particularly because important state examinations are taken at this time. In the UK, a statement of special education needs as in Louise's case can provide extra assistance in the classroom setting. After age 14 years, the Annual Review for a pupil with special education needs should include a transition plan for the move into further education. We advocate that this is vital for all young people with a chronic illness whether they have a statement or not. Drug side effects may also be detrimental, for example, corticosteroids can impair concentration and disturb sleep.

Conversely, cognitive development influences the chronic illness in that not all "chronological" adolescents will have the same intellectual ability to understand their illness. Communication and counselling about the disease and treatment for Louise required acknowledgement of her respective stages of cognitive development. At disease onset it was further complicated by her depressed mood. Berry et al reported that adolescents with JIA answered questions on arthritis at the concrete operational stage of cognitive development, more characteristic of younger children and unlike that of adults. ${ }^{14}$ At the concrete operational stage, children are capable of limited logical thought processes, as in seeing relationships and classifying, as long as manipulable, concrete materials are available. According to Piaget's theory of cognitive development, logical and abstract reasoning usually develops in adolescence, enabling function at the formal operational level, the level that reflects adult levels of understanding and thinking. ${ }^{15}$ This therefore highlights the difference between adolescents and adults in the ways they interpret, understand and respond to their arthritis and their treatment. Another finding from this study was a significant level of inaccuracies and misunderstandings about causes of arthritis and its symptoms despite the fact that many were long time clinic attendees. $^{14}$

In addition to her physical and cognitive development, Louise's psychosocial development was affected by her arthritis. Louise had difficulty establishing relationships with her peers, a situation compounded by her significant absence from school. Problems may continue in adulthood. Wirrel et al report lower perceived social functioning scores in young adults with JIA that did not correlate with degree of physical disability or arthritis subtype. ${ }^{16}$ In addition to their physical disease, it is also important to consider issues of self esteem and coping skills in patients with JIA with all degrees of disability. JIA may also influence the emerging sexuality of the young 
Table 2 Aide memoire for important generic issues in adolescent health care

\begin{tabular}{ll}
\hline Adolescent & HEADS \\
\hline $\mathbf{H}$ & - Home \\
$\mathbf{E}$ & - Education \\
& - Eating/nutrition \\
$\mathbf{A}$ & - Activities \\
& - Ambitions \\
& - Affect, depression, suicide \\
$\mathbf{D}$ & - Drugs, alcohol \\
$\mathbf{S}$ & - Sex
\end{tabular}

person in a variety of ways, for example, delayed puberty, physical limitations, pain, fatigue, depression, feeling unattractive, medication side effects. Furthermore, part of the maturation process necessary for the attainment of adult intimacy and sexuality includes increasing independence from the family, which is often impeded by the presence of a chronic illness like JIA.

Conversely, the psychosocial development may impact on JIA itself. The "risk taking behaviours" familiar to this age group, for example, illegal drug use, smoking and alcohol consumption may potentially affect the management of JIA. Although Louise denies alcohol and sexual activity, anticipatory guidance should continue during follow up especially if methotrexate is continued and Microgynon discontinued.

IS IT IMPORTANT TO CONSIDER GENERIC HEALTH ISSUES IN THE HOSPITAL SETTING?

Louise presented several generic health issues in the hospital setting including lack of general exercise, smoking, concern regarding her weight and menorrhagia. Although health professionals are only one of many sources of health related information used by young people, we must ensure such generic issues as described above are being tackled by someone whether it be by primary or secondary healthcare services in view of their impact on their chronic illness. For many adolescents the relationship with their specialist is closer and often used for both primary and secondary health matters. Carrol et al reported that adolescents with chronic illness in the USA reported more age related concerns such as alcohol and drug issues, periods, sexual health, worry about height and weight, etc, than their healthy peers. ${ }^{17}$ The HEADS pneumonic is a useful aide memoire to adopt in daily clinical practice (table 2).

Although Louise had received physiotherapy in the past, she denied participation in regular general exercise. Klepper et al reported reduced fitness in children with polyarticular JIA compared with controls though lack of fitness was not associated with the activity of the arthritis. ${ }^{18}$ In a case-control study of young adults with JIA, in addition to a lower health perception, lower levels of physical functioning and higher levels of fatigue, a lower level of general exercise was observed in the adults with JIA compared with their healthy peers. ${ }^{6}$ Weight bearing exercise is important in view of the risk of osteoporosis, especially for those taking long term corticosteroids like Louise.
Key messages

- Adolescents are not large children nor small adults.

- Chronic illness and adolescent development (physical, cognitive and psychosocial) are interdependent.

- Transition is a process and not an event.

- Transitional care programmes must be developmentally appropriate and coordinated linking health, education and social services.

Just as parents may be reluctant to raise the topic of sexuality with their healthy children never mind their child with JIA, ${ }^{19}$ so are many health professionals who have been involved with a young person with JIA since early childhood. Nevertheless, chronically ill adolescents do become sexually active at rates comparable to healthy teenagers ${ }^{20}$ and sexual health issues should be sensitively discussed. Seeing the young person independently from the parent may help provide the privacy for such discussion.

For all these issues it is important to emphasise the confidentiality of the consultation. In a study of adolescents in primary care, confidentiality was their major priority when surveyed as to the most important attributes of an adolescent friendly practice. ${ }^{21}$

WERE VOCATIONAL ISSUES CONSIDERED APPROPRIATELY?

Louise was succeeding in her education against the odds, an observation borne out by the literature, which reports educational achievement in patients with JIA to be average or above average at both secondary and tertiary levels. ${ }^{62-25}$ Louise however, still has no idea what she will do when she leaves school. Furthermore she has not had any prior work experience and her parents remain very protective towards her-that is, there are several vocational issues still to be resolved.

Higher levels of unemployment have been reported in JIA patients compared with the local population ${ }^{22}$ and in these studies unemployment did not correlate with educational achievement. The concept of vocational readiness has been described by vocational rehabilitation specialists in North America ${ }^{25}{ }^{26}$ and several centres have established programmes of vocational counselling and career development specifically for young people with chronic illnesses including JIA, for example, the Adolescent Employment Readiness Centre (AERC), Children's National Medical Centre, Washington DC. Vocational readiness is not only related to educational achievement but also to prior work experience, expectations of both the young person, their family and their health professional, psychological factors, for example, self esteem, extent of knowledge about career services and community resources, as well as societal attitudes towards disability. ${ }^{26}$ All these aspects need to be considered by health professionals and careers counsellors of young people with chronic illnesses 
like JIA. Interestingly, when young people with chronic illness and/or disabilities are surveyed, the main areas of demand for service provision include job training and independent living skills $^{27}$ and careers counselling (H E Foster, Newcastle upon Tyne, 1998). Preliminary data from a national study of what adolescents with a wide range of chronic illnesses including JIA want report early and appropriate career counselling, mentoring and information about benefits (B Beresford, University of York, 1998). Unfortunately, these needs are not presently met by service provision with only $9 \%$ of transition programmes in the USA offering career counselling $^{28}$ and only half of the adolescent rheumatology transition programmes in the UK having easy access to disabled employment officers (McDonagh J E, unpublished data). Young people with JIA are not very different from their peers in these matters. Job security and future employment are included in the top five concerns of healthy 15-16 year olds in the UK. ${ }^{29}$

HOW DO YOU FACILITATE INDEPENDENCE IN HEALTH CARE?

Louise is now being seen independently in the adolescent rheumatology clinic though her parents are still accompanying her to and from visits. She also remains dependent on her mother to administer the subcutaneous methotrexate. Independent visits in primary health care are recognised to begin at around 14-15 years ${ }^{30}$ with approximately $50 \%$ of attendances by 15 year olds being independent and slightly higher rates observed in male adolescents. ${ }^{31}$

Anyone who cares for adolescents should be aware of the legislation of decision making in this age group in their country. The legal age for transformation from child to adult is set at 16 years of age in the UK. However, the Gillick test case defines "Gillick competence" for under 16 year olds as those who are considered mature enough to understand the implications of their decision. ${ }^{32}$ Furthermore, the 1989 Children Act has clarified that parents have duties and obligations to children, not rights over them, allowing more leeway in decisions on treatment of those under 16 years. ${ }^{33}$ Young people under 16 years of age however cannot legally refuse treatment but consent is important for compliance. After receiving counselling about the potential side effects of cyclosporin, which include such cosmetic effects as gum hyperplasia and hirsuitism, Louise decided against it. She was however willing to compromise and try an alternative drug. In the care of adolescents with chronic illness, compromise is often a realistic alternative to optimum care. It is vital that children and young people are involved in decision making with respect to their illness from an early age to nurture the development of self advocacy and autonomy as they grow up. Several surveys of adolescent clinics confirm this with young people reporting a need for information about JIA and treatment options (Foster HE, Newcastle upon tyne, 1998; Lang B, Halifax, Canada, 1998) and involvement in decision making (Lang B, Halifax, Canada, 1998). It is important to bear
Table 3 Tasks of adolescence ${ }^{35}$

1 To consolidate their identity

2 To establish relationships outside the family

3 To achieve independence from parents

3 To achieve indepen
To find a vocation

Table 4 Transitions for an adolescent with $\mathcal{F I A}$

1 Paediatric $\rightarrow$ Adult health care

2 School $\rightarrow$ Work/further education/training

3 Family $\rightarrow$ Independent living

in mind that in those young people diagnosed in early childhood, much of the initial disease education will be via the parents and not primarily to them. Disease education and counselling must be age and developmentally appropriate (see above). Sadly, a recent audit of adolescent rheumatology services in the UK identified a current deficiency of patient information resources specifically directed to adolescents (McDonagh J E, unpublished data).

WHAT IS THE DIFFERENCE BETWEEN TRANSITION AND TRANSFER AND AT WHAT AGE SHOULD THEY HAPPEN?

Transition is defined as "a multifaceted, active process that attends to the medical, psychosocial, and educational-vocational needs of adolescents as they move from child-oriented to adult-oriented life-styles and systems". ${ }^{34}$ Transition is a process that ideally should begin on the day of diagnosis ${ }^{34}$ and by age 11 years at the latest. Health professionals must remember that in addition to their chronic illness and the transition to adult health care, adolescents with JIA must accomplish the tasks of adolescence (table 3), ${ }^{35}$ in addition to negotiating two further important transitions (table 4). These tasks and transitions are interdependent and the transitions will not be successful if the tasks are not accomplished.

The aims of transition are:

(1) To provide coordinated, uninterrupted healthcare that is age developmentally appropriate and comprehensive;

(2) to promote skills in communication, decision making, assertiveness and self care;

(3) to increase sense of control and independence of healthcare.

Transfer is an event within the transition process when the young person moves from paediatric into adult care. The timing of transfer depends on many factors and not just chronological age (table 5). There had been no formal transition planning in the early stages of Louise's disease and as the same personnel were in the adolescent clinic, her transfer there at age 15 years was uneventful. Transfer to adult care was discussed before the event when she was 18 years old when her arthritis was well

Table 5 Determinants of readiness for transfer to adult healthcare

- Chronological age

- Maturity

- Medical status

- Compliance

- Availability of adult specialist

- Independence

- Adolescent readiness 
controlled. There were still several unresolved issues that need to be considered in the adult rheumatology clinic (table 1).

\section{WHAT PART DO THE PARENTS PLAY IN THE} TRANSITION PROCESS?

One of the main differences between paediatric and adult care is with respect to the parents. The consultation dynamics in paediatric healthcare are triangular with interaction between child, parent and doctor. In adult practice this becomes linear with interaction between the young adult and doctor. In adolescent care these interactions evolve and may at times be a combination of both as the adolescent gradually gains confidence and competence in the art of self advocacy. During this evolution however the parent(s) must be supported and encouraged to become an advocate for their offspring and not abruptly exiled to the waiting area immediately their child turns 16. Louise's parents tended to be over protective as exemplified by the maternal supervision of Louise's medication and the level of concern regarding her first major venture towards independence - that is, learning to drive. Expectations of parents for their child with JIA are important as they may be too high or too low. In one study, although parents of non-disabled patients with JIA denied any impact of the disease on their child, they still had lower expectations for their education compared with their healthy siblings. ${ }^{36}$ Only $17 \%$ of parents expected their non-disabled child with JIA to go to university compared with $73 \%$ of their healthy siblings. ${ }^{36}$ When 100 adolescents with chronic illness and/or physical disabilities were studied, their lack of career maturity and paucity of early work experience related to their parents view that the mean age for first work experience should be 16 years or older. ${ }^{37}$ This is compared with reports of $50 \%$ healthy 13 year olds are involved in work experience outside their home. ${ }^{38}$ Parents therefore need to be supported, made aware of resources available and encouraged to ensure that their child attains the functional living skills and develops autonomy and self advocacy skills equivalent to their healthy peers. The positive, affirming role of the family must not be forgotten in the attempts to engender increasing adolescent independence. Family connectedness, family role models, family concern for the well being of the child and autonomy at home are all factors identified that foster resilience in children and should be encouraged and affirmed, ${ }^{39}$ especially at this time.

WHAT BARRIERS OF TRANSITION DID THIS YOUNG WOMAN ENCOUNTER?

Louise has not had a smooth transfer to adult care. Certain barriers can be identified with respect to the key people involved.

The young person

Louise had been looked after by a well established, multi-disciplinary team for several years. It is a consultant-based service and she were seen by either of the two consultant paediatric rheumatologists at every visit, whether or not she was seen by a trainee first. Louise had difficulty establishing relationships and it took time to gain her confidence in the paediatric clinic. To be seen by an inexperienced trainee with no contact with the consultant adult rheumatologist at the first visit to the adult service failed to instil confidence in either Louise or her parents and led to a delay in final transfer and continuing visits to the paediatric service.

Louise also has severe disease. Ideally transfer should take place during a period of remission as in Louise's case. It should be remembered that it is not just those with severe disease who have problems at transition. The concept of "invisible disability" is supported by the lack of correlation between the level of functional ability and employment status, ${ }^{22}$ career maturity $^{37}$ and emotional problems ${ }^{40}$ in JIA. The unpredictability of JIA is an important component of "invisible disability".

Louise was still not totally independent in terms of her health care at the time of transfer and had not yet been able to self inject methotrexate. Louise's parents still insist in attending hospital with Louise despite her having her own transport. The opportunity for Louise to talk to the health professionals alone has been fruitful revealing her smoking habit and her secret boyfriend. Independent visits should be facilitated within the clinic, to permit issues such as concerns regarding sexual health, relationship problems with over protective parents, to be expressed and explored.

\section{The parent(s)/guardian(s)}

The close relationship between the parent and the paediatric team may also be a barrier to transition and transfer as can their lack of confidence in adult team, as occurred in Louise's case. Parental over protection and reluctance to "let go" of their child may be further hurdles.

\section{Healthcare delivery}

Adult rheumatology services are frequently different from paediatric rheumatology services in terms of time available for consultation, continuity of care in terms of the same doctor at consecutive visits and the format of referrals to allied professions, which in smaller adult services are often paper referrals rather than personal within a rheumatology team.

Most adult rheumatologists have not received any paediatric training since leaving medical school and may not be confident in managing adolescents who are still developing and maturing. The familiar two way adult consultation of patient and doctor is still triangular in adolescent practice with the parent evolving from a primary to secondary advocacy role. Finally, it is important for health professionals in the adult sector to reflect on their own feelings towards adolescents whether they be disapproving or envious. Some professionals may simply not like looking after adolescents and find their non-compliance and uncommunicative behaviours an irritation in an adult clinic. 
Table 6 Comparison between adolescent and adult rheumatology practice

- Different disease

- Impact of disease

- Adolescent development

- Consultation dynamics

- Communication skills

- Role of parents/family

- Legal issues

- Generic adolescent issues

\section{Conclusions}

Louise is an example of many such young people with JIA in our rheumatology clinics. Her story is not unusual or special but serves to highlight important issues pertinent to the care and management of adolescents with a chronic illness like JIA. Many of the areas of need highlighted are not specific to adolescents, for example, vocation, sexuality, compliance are equally true for adults with chronic illnesses. Similarly, the need for multi-disciplinary, interagency care is as much true for adult as for adolescent rheumatology. However the differences must also be acknowledged - that is, that JIA is a different spectrum of diseases than adult rheumatic diseases; that the reciprocal influences of chronic illnesses and adolescent development are important and the evolving role of the family must be recognised (see also table 6). Recent literature supports the need for development in this area with several UK studies reporting a decline in quality of medical care for physically disabled young people after transfer to adult services. ${ }^{41-43}$ Conversely, quality of life, albeit ill defined, seems to improve with formal transitional care programmes in $\mathrm{JIA}^{44}$ as well as other chronic diseases, for example, cystic fibrosis ${ }^{45}$ and diabetes. ${ }^{47} 48$ Adolescent rheumatology is an area ripe for research and investigation for both paediatric and adult rheumatologists, for example, whether transitional care programmes influence clinical outcome or quality of life, or both, as measured by a validated index, for example, Juvenile Arthritis Quality of life questionnaire JAQQ.$^{49}$ Adult and paediatric rheumatologists must work closely together to provide the coordinated, uninterrupted, medically excellent, age and developmentally appropriate transitional care these young people deserve to help them grow up into independent and fulfilled adults who happen to have JIA.

The name of the patient has been changed. JMcD wishes to thank the Royal College of Physicians and Surgeons of Glasgow for awarding her a travelling fellowship to the AERC, Washingfor awarding her a travelling fellowship to the AERC, Washington, DC in 1998 and Professor Patience White and
the AERC for their valuable support and training.

1 Singh G, Athreya B, Fries J, Goldsmith DP, Ostrov BE. Measurement of health status in children with juvenile rheumatoid arthritis. Arthritis Rheum 1994;37:1761-9. 2 Viner R, Keane $M$. Youth matters: evidence-based best practice
for the care of young people in hospital. London: Action for Sick Children, 1998 .

3 Petty RE, TR Southwwod, Baum J, Bhettay E, Glass DN, Manners $\mathrm{P}$, et al. Revision of the proposed classification criteria for juvenile idiopathic arthritis: Durban, 1997. J Rheumatol 1998;25:1991-4.

4 Gare BA, Fasth A. The natural history of juvenile chronic arthritis. A population based cohort study. II. Outcome. J Rheumatol 1995;22:308-19.

5 David J, Cooper C, Hickey L, Lloyd J, Dore C, McCullough $\mathrm{C}$, et al. The functional and psychological outcomes of $\mathrm{C}$, et al. The functional and psychological outcomes of
juvenile chronic arthritis in young adulthood. $\mathrm{Br}$ J juvenile chronic arthritis in
Rheumatol 1994;33:876-81.
6 Petersen LS, Mason T, Nelson AM, et al. Psychosocial outcomes and health studies in adults who have had juvenile arthritis: a controlled population based study. Arthritis Rheum 1997;40:2235-40.

7 Ruperto N, Levinson JE, Ravelli A, Shear ES, Tague BL, Murray $\mathrm{K}$, et al. Long-term health outcomes and quality of life in an american and italian inception cohort of patients with juvenile rheumatoid arthritis. I. Outcome status. J Rheumatol 1997;24:945-51.

8 Pepmueller P, Cassidy J, Allen S, Hillman L. Bone mineralisation and bone mineral metabolism in children with juvenile rheumatoid arthritis. Arthritis Rheum 1996;39:74657 .

9 Stewart RB, Claff LE. Review of medication errors and compliance in ambulatory patients. Clin Pharmacol Ther 1972;13:463-5

10 Wolman C, Resnick MD, Harris LJ, Blum RW. Emotional well-being among adolescents with and without chronic conditions. J Adolesc Health 1994;15:199-204.

11 Stanhope R. Endocrinology. In: Brook C, ed. The practice of medicine in adolescence. London: Edward Arnold, 1993: $120-46$

12 Fraser P, Hoch S, Erlandson D, et al. The timing of menarche in juvenile rheumatoid arthritis. J Adolesc Health Care 1988;9:483-7.

13 Lovell D, Athreya B, Emery H, Gibbas DL, Levinson JE, Lindsley CB, et al. School attendance and patterns, special services and special needs in paediatric patients with rheumatic diseases. Arthritis Care Res 1990;3:196-203.

14 Berry SL, Hayford JR, Ross CK, et al. Conceptions of illness by children with juvenile rheumatoid arthritis: a cognitive developmental approach. J Pediatr Psychol 1993;18:83-97.

15 Piaget J. Intellectual evolution from adolescence to adulthood. Human Devel 1972;15:1-12.

16 Wirrell E, Long B, Canfield C. Social outcome in young adults with juvenile arthritis: implication for the development of transition clinics. Arthritis Rheum 1995:38:S184.

17 Carroll G, Massarelli E, Opzoomer A, Pekeles G, Pedneault $\mathrm{M}$, Frappier JY, et al. Adolescents with chronic disease: are they receiving comprehensive health care? J Adolesc Health Care 1983;17:32-6.

18 Klepper S, Darbee J, Effgenr SK, Singsen BH. Physical fitness levels in children with polyarticular juvenile rheumatoid arthritis. Arthritis Care Res 1992;5:93-100.

19 Zuengler KL, Neubeck G. Sexuality: developing togetherness. In: McCubben H, ed. Stress and the family. New York: Bruner/Mazel, 1983:41-3

20 Choquet M, Fediaevsky LDP, Manfredi R. Sexual behaviour among adolescents reporting chronic conditions: a French national survey. J Adolesc Health 1997;20:62-7.

21 McPherson A. Primary health care and adolescence. In: MacFarlane A, ed. Adolescent medicine. London: Royal College of Physicians, 1996:33-41.

22 Martin K, Woo P. Outcome in juvenile chronic arthritis. Rev Rhum Engl Ed 1997;10:S242.

23 Miller J, Spitz P, Simpson U, Williams G. The social function of young adults who had arthritis in childhood. J Paediatr 1982;100:378-82

24 Hill R, Herstein A, Walters K. Juvenile rheumatoid arthritis: follow-up into adulthood - medical, sexual and social status. Can Med Assoc J 1976:114:790-6.

25 White PH, Shear ES. Transition/job readiness for adolescents with juvenile arthritis and other chronic illnesses. J Rheumatol 1992;19:23-7.

26 White PH. Educational and vocational planning - the key to success in adulthood. Isenberg DA, Miller JJ, eds. Adolescent rheumatology. London: Martin Dunitz, 1999: 273-90

27 Wright B. Teens say job training their top need. Point of Departure - A publication of the technical assistance about training on the rehabilitation Act Project - PACER Center 2:8. Minnesota MN: PACER, 1996.

28 Transition planning for the twenty-first century: a call to action. Minneapolis, MN: National Centre for Youth with Disabilities, 1995:14

29 Oakley A, Bendelow G, Barnes J, Buchanan M, Nasseem Hussain OA. Health and cancer prevention: knowledge and beliefs of children and young people. BMJ 1995;310:102933.

30 Jacobson L, Owen P. Study of teenage care in one general practice. Br J Gen Pract 1993;43:349.

31 Balding J. Young people into the nineties. Book 1. Doctor and dentist. Exeter: University of Exeter, Schools Health Education Unit, 1991

32 Pickersgill D, ed. The law and general practice. Oxford: Radcliffe Medical Press, 1992.

33 White R, Carr P, Lowe N. A guide to the Children Act 1989. London: Butterworths, 1990 .

34 White PH. Success on the road to adulthood. Issues and hurdles for adolescents with disabilities. Rheum Dis Clin N Am 1997;23:697-707.

35 Strax TE. Psychological issues faced by adolescents and young adults with disabilities. Pediatr Ann 1991;20:501-6.

36 McAnarney ER, Pless IB, Satterwhite B, Friedman SB. Psychological problems of children with chronic juvenile arthritis. Pediatrics 1974;53:523-8.

37 White PH, Gussek DG, Fisher B, et al. Career maturity in adolescents with chronic illness. J Adolesc Health Care 1990;11:372.

38 Phillips S, Sandston KL. Parental attitudes toward work. Youth and Society 1990:22:160. 
39 Patterson J, Blum RJ. Risk and resilience among children and youth with disabilities. Arch Pediatr Adolesc Med $1996 ; 150: 692-8$

40 Baildam EM, Holt PJL, Conway SC, Morton MJS. The association between physical function and psychological problems in children with juvenile chronic arthritis. $\mathrm{Br} \mathrm{J}$ Rheumatol 1995;34:470-7.

41 Florentino L, Datta D, Gentle S, Hall DMB, Harpin V, Phillips D, et al. Transition from school to adult life for physically disabled young people. Arch Dis Child 1998;79: 306-11.

42 Stevenson CJ, Pharoah POD, Stevenson R. Cerebral palsy the transition from youth to adulthood. Dev Med Child Neurol 1997;39:336-42.

43 Bax MC, Smyth DP, Thomas AP. Health care of physically handicapped young adults. BMJ 1988;296:1153-5.

44 Rettig P, Athreya BH. Adolescents with chronic disease: transition to adult health care. Arthritis Care Res transition to
45 Capelli M, MacDonald NE, McGrath PJ. Assessment of readiness to transfer to adult care for adolescents with cystic fibrosis. Children's Health Care 1989;18:218-24.

46 Nasr SZ, Campbell C, Howatt W. Transition program from paediatric to adult care for cystic fibrosis patients. J Adolesc Health 1992;13:682-5.

47 Sawyer SM. The process of transition to adult health care services. In: Werther G, Court J, eds. Diabetes and the adoservices. In: Werther G, Court J, eds.
lescent. Melbourne: Blackwell, 1998.

48 Salmi J, Huuponen T, Oksa H, Oksala H, Koivula T, Raita P. Metabolic control in adolescent insulin-dependent diabetics referred from pediatrc to adult clinic. Ann Clin Res 1986;4:174-80.

49 Duffy CM, Arsenault L, Watanabe Duffy KN, Paquin JD, Strawczynski H. The Juvenile Arthritis Quality of Life Questionnaire - Development of a new responsive index for juvenile rheumatoid arthritis and juvenile spondyloarthritides. J Rheumatol 1997;24:738-46. 